\title{
Neuromuscular transmission in myasthenia gravis studied with single fibre electromyography ${ }^{1}$
}

\author{
ERIK STÅLBRG ${ }^{2}$, JAN EKSTEDT ${ }^{3}$, AND ANDERS BROMAN \\ From the Department of Clinical Neurophysiology and \\ the Department of Neurology, University of Uppsala, Sweden
}

SYNOPSIS Patients with myasthenia gravis have been investigated with single fibre electromyography. In all myasthenic muscles recordings were obtained where there was an increase of the jitter and occasional blocking of different degree of single fibre action potentials. The jitter is the variability at consecutive discharges in the time interval between action potentials from two muscle fibres from the same motor unit. During prolonged activity the jitter increased and blockings occurred more and more frequently. The size of the jitter and the degree of blocking also depended on the discharge rate. At a low rate the jitter was lower and the degree of blocking less than at the high rate. Injection of edrophonium could decrease or increase the jitter or leave it unaffected. Single fibre electromyography is a sensitive way of studying the transmission in individual motor end-plates in myasthenia gravis and is also a valuable diagnostic aid.

The electromyogram, obtained with concentric needle electrodes, often shows typical changes in myasthenia gravis (Lindsley, 1935). During activity there is a decrease of the amplitude and a splitting of the motor unit action potentials.

Complementary information can be obtained by electrical stimulation of the nerve during electromyographic recording (Harvey and Masland, 1941). In the normal muscle, stimulation at a rate of up to $10 \mathrm{~Hz}$ can be maintained for a long time without a decrease in amplitude or alteration in shape of the recorded action potential. In a myasthenic muscle, however, action potentials will be broken down within a period that depends on the stimulation rate and on the severity of the disease. When using an electrode that leads off activity from many fibres, the potential amplitude will decrease grossly proportionally to the number of fibres to which the transmission has been blocked. In myasthenia gravis the first few action potentials obtained

\footnotetext{
1 This investigation was supported by the Swedish Medical Research Council (Grant no. 14 X-135).

2 Address for correspondence: Dr Erik Stålberg, Department of Clinical Neurophysiology, University Hospital, S-750 14 Uppsala, Sweden.

3 Address for correspondence: Dr. Jan Ekstedt, Department of Neurology, University Hospital, S-750 14 Uppsala, Sweden.
}

after a pause, after a period of tetanic stimulation, are usually of increased amplitude (post-tetanic potentiation).

When recording the action potentials from two single muscle fibres belonging to the same motor unit, Ekstedt (1964) found that there is always a slight variability in the time interval between the two potentials in such a 'potential pair'. This variability, the jitter, is normally of the order of magnitude of $20 \mu \mathrm{sec}$ (Stålberg et al., 1971). The main cause of the jitter is probably the uncertainty in the synaptic delay in the two motor end-plates (Ekstedt, 1964; Ekstedt and Stålberg, 1969; Ekstedt and Stålberg, 1973). In earlier reports (Ekstedt and Stålberg, 1965, 1967; Blom and Ringqvist, 1971; Stålberg and Ekstedt, 1973; Stålberg and Hansson, 1973), it has been shown that the jitter is increased in patients with myasthenia gravis and that this may be used as an early diagnostic sign.

This investigation is aimed at studying the neuromuscular transmission in individual endplates in myasthenia gravis. The influence of the innervation rate and of injection of edrophonium has been especially studied. 


\section{METHODS}

Detailed descriptions of single-fibre electromyography can be found in Ekstedt (1964), Stålberg (1966), Czekajewski et al. (1969), Ekstedt and Stålberg (1969), Stålberg et al. (1971), and Ekstedt and Stålberg (1973). In short, recordings are made with a needle multielectrode (Ekstedt et al., 1969) with 14 platinum leading-off surfaces $(25 \mu \mathrm{m}$ in diameter) in the side of a $0.5 \mathrm{~mm}$ injection cannula or, with an electrode of similar design, with only two leading-off surfaces. Jitter was measured as mean consecutive difference (Ekstedt et al., 1974) (MCD) of 50-200 interpotential intervals. Normal values are of the order of $20 \mu$ s (Stålberg et al., 1971). The measurement was made either on the computer after recording of the time intervals on the digital tape or directly, at the time of experiment, by means of the jittermeter (Ekstedt et al., 1971).

We investigated 32 patients with the clinical diagnosis of myasthenia gravis (23 women and nine men). Ages ranged from 12 to 75 years. The duration of the symptoms varied between six months and 23 years.

Twenty-eight of the 32 patients were on cholinesterase-inhibitor therapy: neostigmine (Prostimine,

TABLE

JITTER IN TOTAL MATERIAL OF 32 PATIENTS

\begin{tabular}{|c|c|c|c|c|c|c|c|}
\hline \multirow[t]{2}{*}{ Patient } & \multirow[t]{2}{*}{ Se.x } & \multirow{2}{*}{$\begin{array}{l}\text { Age } \\
(y r)\end{array}$} & \multirow[t]{2}{*}{ Muscle } & \multirow{2}{*}{$\begin{array}{l}\text { Total number } \\
\text { cf potential } \\
\text { pairs recorded }\end{array}$} & \multicolumn{3}{|c|}{ Number of potential pairs with } \\
\hline & & & & & $\begin{array}{c}\text { Normal } \\
\text { jitter }\end{array}$ & $\begin{array}{c}\text { Increased jitter } \\
\text { without } \\
\text { blockings }\end{array}$ & $\begin{array}{c}\text { Highly in- } \\
\text { creased jitter } \\
\text { with blockings }\end{array}$ \\
\hline A.A. & $\mathrm{F}$ & 14 & TA & 4 & 0 & 0 & 4 \\
\hline A.B. & $\mathrm{F}$ & 35 & EDC & 12 & 3 & 2 & 7 \\
\hline \multirow[t]{3}{*}{ B.A. } & $\mathrm{M}$ & 59 & EDC & 3 & 0 & 0 & 3 \\
\hline & & & ADQ & 2 & 1 & 1 & 0 \\
\hline & & & TA & 4 & 3 & 1 & 0 \\
\hline \multirow[t]{2}{*}{ B.B.-M. } & $\mathrm{F}$ & 18 & EDC & 1 & 0 & 1 & 0 \\
\hline & & & BB & 3 & 0 & 2 & 1 \\
\hline \multirow[t]{3}{*}{ B.D. } & $\mathrm{F}$ & 31 & EDC & 10 & 0 & 2 & 8 \\
\hline & & & BB & 10 & 0 & 2 & 8 \\
\hline & & & TA & 10 & 0 & 5 & 5 \\
\hline E.B.-M. & $F$ & 24 & EDC & 15 & 0 & 5 & 10 \\
\hline E.G. & $\mathrm{F}$ & 29 & EDC & 26 & 0 & 15 & 11 \\
\hline \multirow[t]{2}{*}{ F.L. } & $\mathrm{F}$ & 73 & EDC & 5 & 0 & 0 & 5 \\
\hline & & & TA & 5 & 0 & 0 & 5 \\
\hline G.B. & M & 45 & EDC & 35 & 2 & 18 & 15 \\
\hline G.L. & $\mathbf{F}$ & 24 & EDC & 1 & 0 & 0 & 1 \\
\hline G.M. & $\mathrm{F}$ & 23 & EDC & 15 & 0 & 8 & 7 \\
\hline H.A. & M & 75 & EDC & 1 & 0 & 1 & 0 \\
\hline H.A.-G. & $\mathbf{F}$ & 35 & EDC & 50 & 0 & 8 & 42 \\
\hline \multirow{2}{*}{ H.P.-O. } & M & 40 & EDC & 12 & 7 & 4 & 1 \\
\hline & & & EDC & 5 & 2 & 3 & 0 \\
\hline \multirow[t]{2}{*}{ I.B. } & $\mathrm{F}$ & 25 & EDC & 40 & 0 & 28 & 12 \\
\hline & & & FR & 6 & 6 & 0 & 0 \\
\hline \multirow{3}{*}{ J.I. } & $\mathrm{F}$ & 22 & EDC & 5 & 0 & 0 & 5 \\
\hline & & & TA & 5 & 0 & 0 & 5 \\
\hline & & & QF & 5 & 0 & 0 & 5 \\
\hline J.M. & $\mathrm{F}$ & 24 & EDC & 9 & 0 & 5 & 4 \\
\hline J.M.O. & M & 33 & EDC & 8 & 0 & 4 & 4 \\
\hline K.B. & $\mathbf{F}$ & 49 & EDC & 15 & 2 & 11 & 2 \\
\hline \multirow[t]{2}{*}{ L.G. } & $\mathrm{F}$ & 29 & EDC & 1 & 0 & 1 & 0 \\
\hline & & & BB & 4 & 0 & 1 & 3 \\
\hline L.K. & $\mathrm{F}$ & 17 & EDC & 3 & 0 & 1 & 2 \\
\hline L.L. & $\mathrm{F}$ & 18 & EDC & 6 & 0 & 3 & 3 \\
\hline M.M. & $\mathrm{F}$ & 43 & EDC & 10 & 7 & 2 & 1 \\
\hline N.A. & M & 15 & EDC & 4 & 0 & 3 & 1 \\
\hline O.H.-O. & M & 40 & EDC & 5 & 1 & 1 & 3 \\
\hline O.I. & $\mathbf{M}$ & 52 & EDC & 7 & 3 & 4 & 0 \\
\hline O.M. & $\mathrm{F}$ & 12 & EDC & 10 & 0 & 5 & 5 \\
\hline \multirow{2}{*}{ S.G. } & $\mathrm{F}$ & 31 & BB & 4 & 2 & 2 & 0 \\
\hline & & & EDC & 4 & 0 & 0 & 4 \\
\hline S.K. & $\mathrm{F}$ & 32 & EDC & 6 & 0 & 2 & 4 \\
\hline T.G. & $\mathbf{M}$ & 52 & EDC & 20 & 0 & 5 & 15 \\
\hline W.M. & $\mathrm{F}$ & 23 & EDC & 9 & 0 & 3 & 6 \\
\hline Ö.E. & $F$ & 32 & EDC & 18 & 0 & 7 & 11 \\
\hline
\end{tabular}

$\mathrm{EDC}=\mathrm{m}$. extensor digitorum communis, $\mathrm{BB}=\mathrm{m}$. biceps brachii, $\mathrm{TA}=\mathrm{m}$. tibialis anterior, $\mathrm{FR}=\mathrm{m}$. frontalis, $\mathrm{ADQ}=\mathrm{m}$. adductor digiti $\mathrm{quinti}$, $\mathrm{QF}=\mathrm{m}$. quadriceps femoris. 
ambestigmine (Mytelase), pyridostigmine (Mestinon). The drug regime was not changed before the investigation.

Fourteen of the patients were thymectomized.

In nine of these patients edrophonium tests were performed during recording.

The special investigations on the effect of innervation rate required the collaboration of the patient and could be performed in nine patients.

Most of the investigations were made in $\mathrm{m}$. extensor digitorum communis but some also in $\mathrm{m}$. biceps brachii and $\mathrm{m}$. tibialis anterior and a few in $\mathrm{m}$. frontalis and $\mathrm{m}$. quadriceps.

\section{RESULTS}

THE JITTER At least 20 jitter recordings were attempted for each patient, but it was often impossible to get this amount for various reasons. Firstly, in a severely affected muscle it proved very difficult to find two muscle fibres from the same motor unit which discharged together often enough for recording the jitter because of a high degree of neuromuscular blocking. Secondly, some patients had extreme difficulty in maintaining a steady contraction. Thirdly, in some recordings the action potentials interfered with each other, making measurement impossible. The results of the jitter measurements in the total material are compiled in the Table.

In a particular myasthenic muscle the following findings could be made in different potential pairs:

A. Potential pairs with highly increased jitter and blockings. The jitter was usually above $100 \mu \mathrm{s}$. The higher the jitter, the more frequent were the blockings (Fig. ID, E).

B. Potential pairs with increased jitter but without blockings. The jitter was then usually less than $80 \mu$ s (Fig. 1B, C).

C. Potential pairs with jitter within the normal range (Fig. 1A).

As seen in Table 1, there were six muscles with all these types of findings on the same experimental occasion. In 20 muscles only types $\mathrm{A}$ and $B$ were found and in five muscles only types B and $C$. In nine muscles all recorded potentials showed blockings.

In patient I.B., where increased jitter and blockings were seen in $\mathrm{m}$. extensor digitorum communis, the six recordings in $\mathrm{m}$. frontalis showed normal conditions.
PROLONGED ACTIVITY As often as feasible, jitter recordings have been made with one and the same potential pair during a long period. For potential pairs where the jitter was already increased at the beginning, there was usually an increase of jitter during the experiment and the blockings occurred more and more frequently.

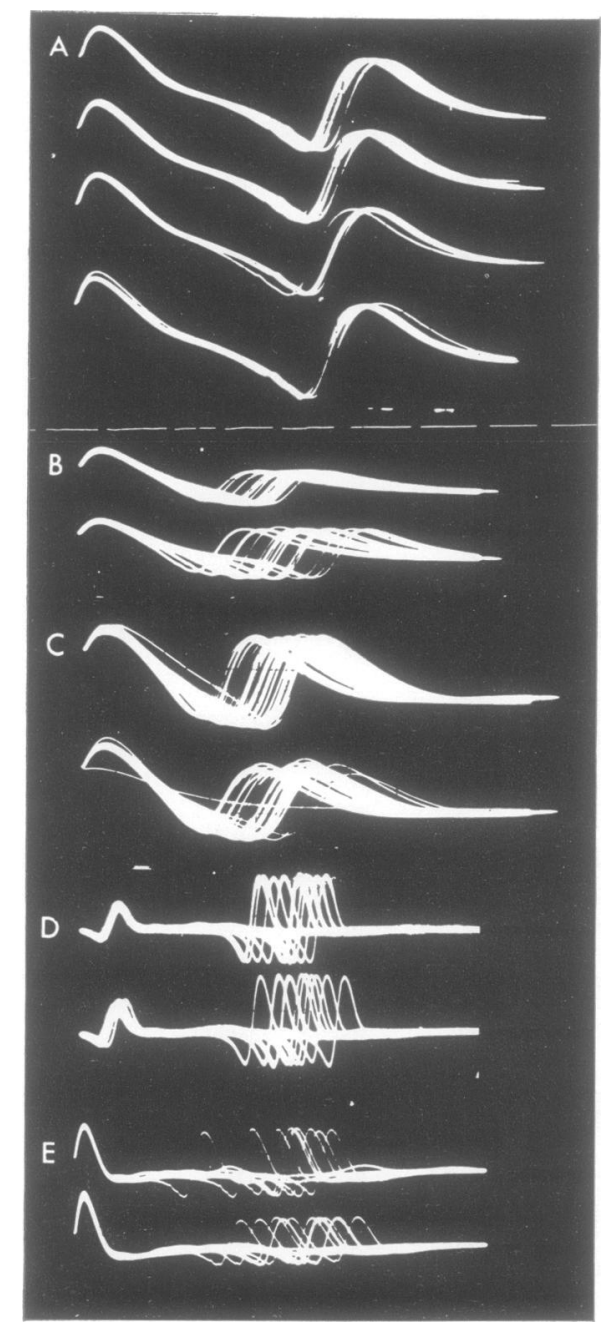

FIG. 1. Examples of jitter recordings in m. extensor digitorum communis. 10-30 discharges have been superimposed in each trace. A: normal subject. The first potential only partially seen. Time base $100 \mu \mathrm{s} /$ $\mathrm{cm}$. Jitter: $15 \mu \mathrm{s}$. B and C: myasthenia gravis, patient I.B. Time base $100 \mu \mathrm{s} / \mathrm{cm}$. Jitter: $70 \mu \mathrm{s}$. $\mathrm{D}$ and $\mathrm{E}$ : myasthenia gravis, patient Ö.E. Time base $500 \mu \mathrm{s} / \mathrm{cm}$. Jitter in D: $270 \mu \mathrm{s}$, in E: $425 \mu \mathrm{s}$. 


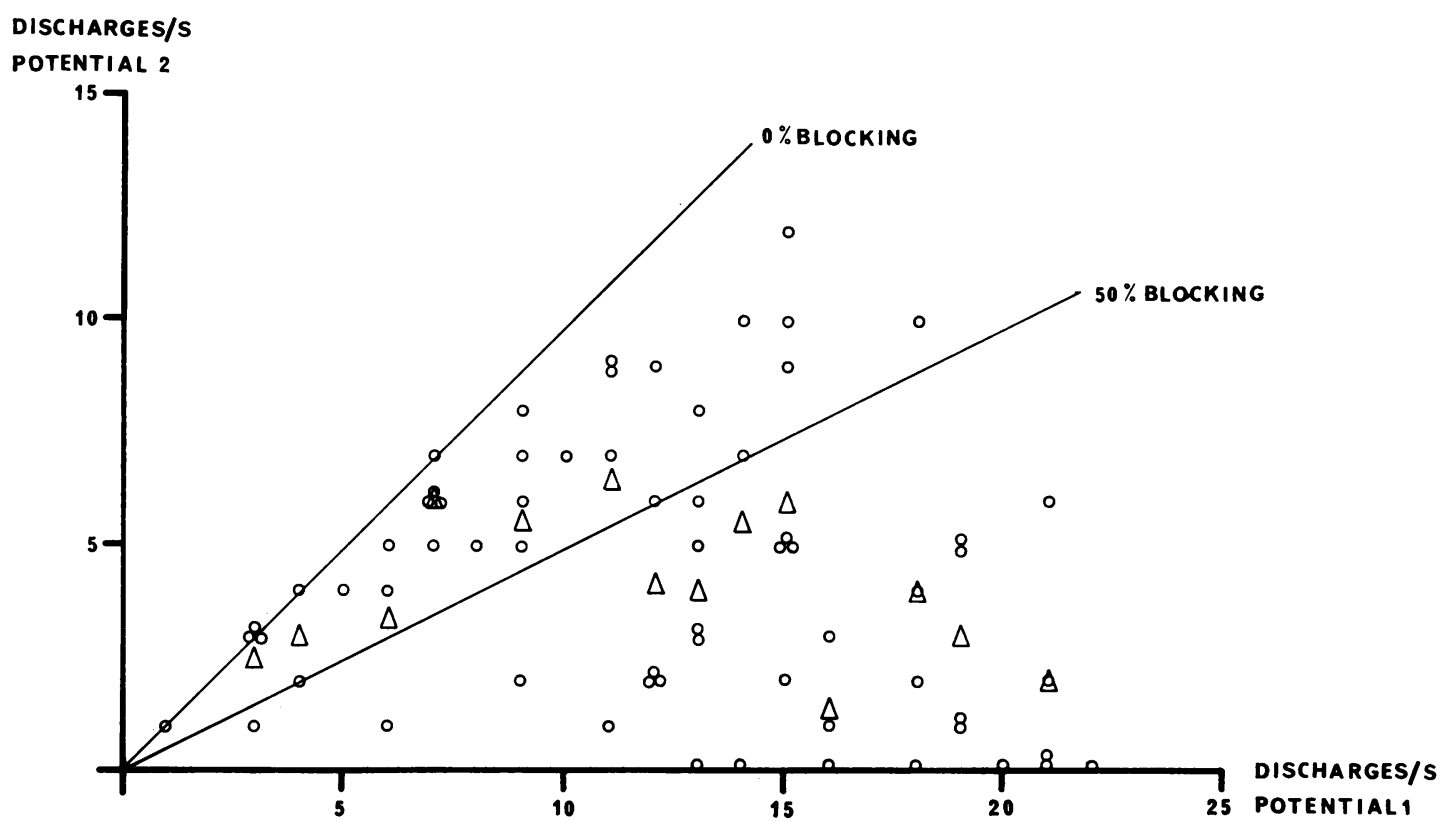

FIG. 2. The effect of increasing innervation rate on the discharge rate of a blocking potential. The abscissa is the innervation rate, equivalent to the discharge rate of action potential 1 in the pair, not blocking. Ordinate: the discharge rate of the partially blocking potential 2. $\bigcirc:$ mean discharge rates during one-second periods. $\triangle:$ mean value of the discharge rate of potential 2 for the different innervation rates. At increasing innervation rate the discharge rate of potential 2 increases. When innervation rate exceeds about $12 \mathrm{~Hz}$ the discharge rate of potential 2 falls.

Potential pairs that initially had blockings usually got an increasing degree of blocking. When the jitter was initially normal, the activity seemed not to affect the size of the jitter.

INFLUENCE OF INNERVATION RATE ON DEGREE OF BLOCKING Three potential pairs were selected from patients B.M.E., A.G.H., and T.G., where one of the potentials was subject to different degrees of occasional blockings. A striking observation was that at a low innervation rate the discharge rate of the blocking potential was only slightly below the innervation rate. When slowly increasing the innervation rate, the degree of blocking increased and the discharge rate of the blocking potential rose more slowly than the innervation rate. At a certain innervation rate the discharge rate began to fall until there was almost a total block (Fig. 2). The changes in the degree of blocking took place within one or a few seconds after a sudden change in the innervation rate. Also when the innervation rate was reason- ably stable the degree of blocking increased with time, but with a slower time course, up to minutes, depending on the innervation rate. In one experiment (E.B.-M.) an interesting observation was made. Three minutes after the start of the experiment the innervation rate was lowered from about 14 to 9-10 discharges per second. One minute after this, there was no longer any blocking in the second potential and a third potential appeared from a fibre that apparently had been totally blocked previously during the experiment. It had a rather high degree of blocking.

SINGLE MUSCLE FIBRE ACTIVITY As mentioned earlier it was sometimes difficult to obtain jitter recordings in severely affected muscles, because two muscle fibres from the same motor unit rarely occurred together. In some of these cases, single muscle fibre action potentials were recorded and analysed with regard to their interdischarge intervals. 


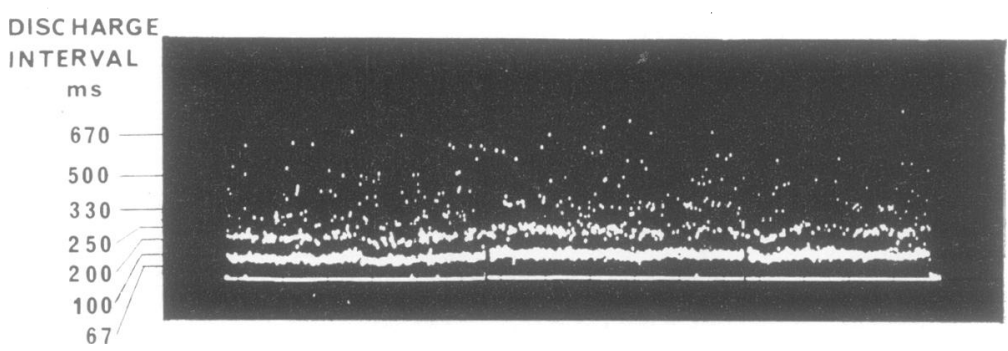

FIG. 3. Distribution of interdischarge intervals in a single muscle fibre action potential subject to blockings. Abscissa: discharge number. About 2,500 discharges are shown. Ordinate: interdischarge interval in ms. The diagram has been made on a CAT 1000. The intervals about $100 \mathrm{~ms}$ are those where there has been no blocking between two discharges. When one discharge fails the values are grouped about $200 \mathrm{~ms}$, when three fail about $300 \mathrm{~ms}$ etc.

In the example in Fig. 3 it is seen that the distribution of time intervals is mainly about a certain mean value, but some intervals fall at double, treble, etc., this mean interval, indicating that some potentials have been missing. The missing of potentials is readily heard in the loudspeaker as a characteristic unevenness of the innervation rate.

EFFECTS OF EDROPHONIUM ON JITTER AND BLOCK-
INGS In nine patients edrophonium (Tensilon) $2 \mathrm{mg}$ was injected intravenously during $15 \mathrm{~s}$ in 11 experiments. After another $45 \mathrm{~s} 8 \mathrm{mg}$ was injected, if there were no adverse reaction on the first dose. Continuous recording was startedo some minutes before the injection and was then continued for several minutes. No tests of the $\stackrel{\mathbb{Q}}{\circ}$ 음 muscular strength were made after the injection of edrophonium because the recording position could not be maintained during gross move-
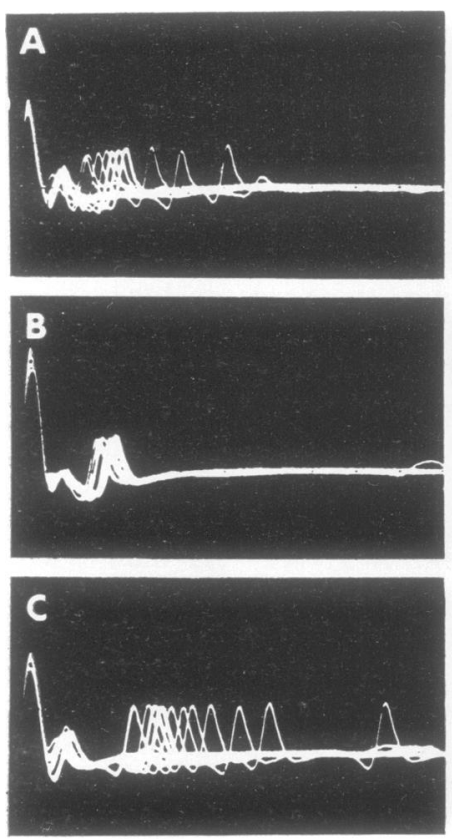
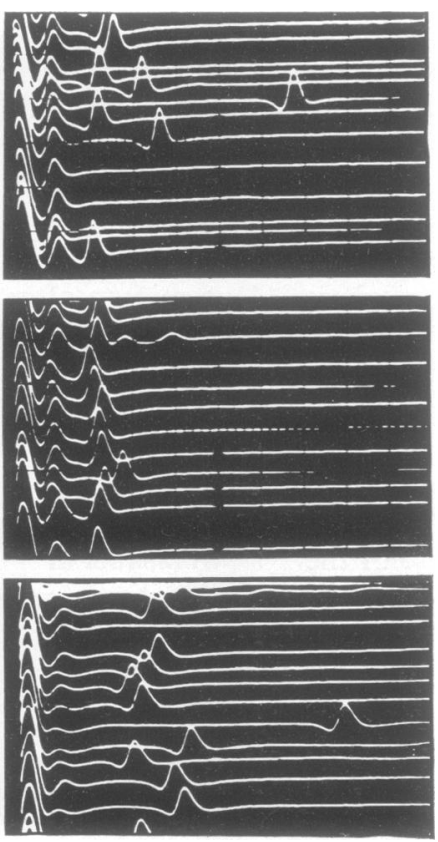

FIG. 4. Jitter recordings in myasthenia gravis. Patient T.G. before (A), two minutes after injection of $2 \mathrm{mg}$ edrophonium (B) and $5 \frac{1}{2}$ min after injection (C). Jitter: in A: $580 \mu s$; in $B: 85 \mu s$; in $C: 700 \mu s$.

In the photographs to the right (exposed some 10 seconds after the ones to the left) the sweeps have been vertically moved during recording to show the blockings in the last potential. There are blockings in $A$ and C. Time base $500 \mu \mathrm{s} / \mathrm{div}$. 


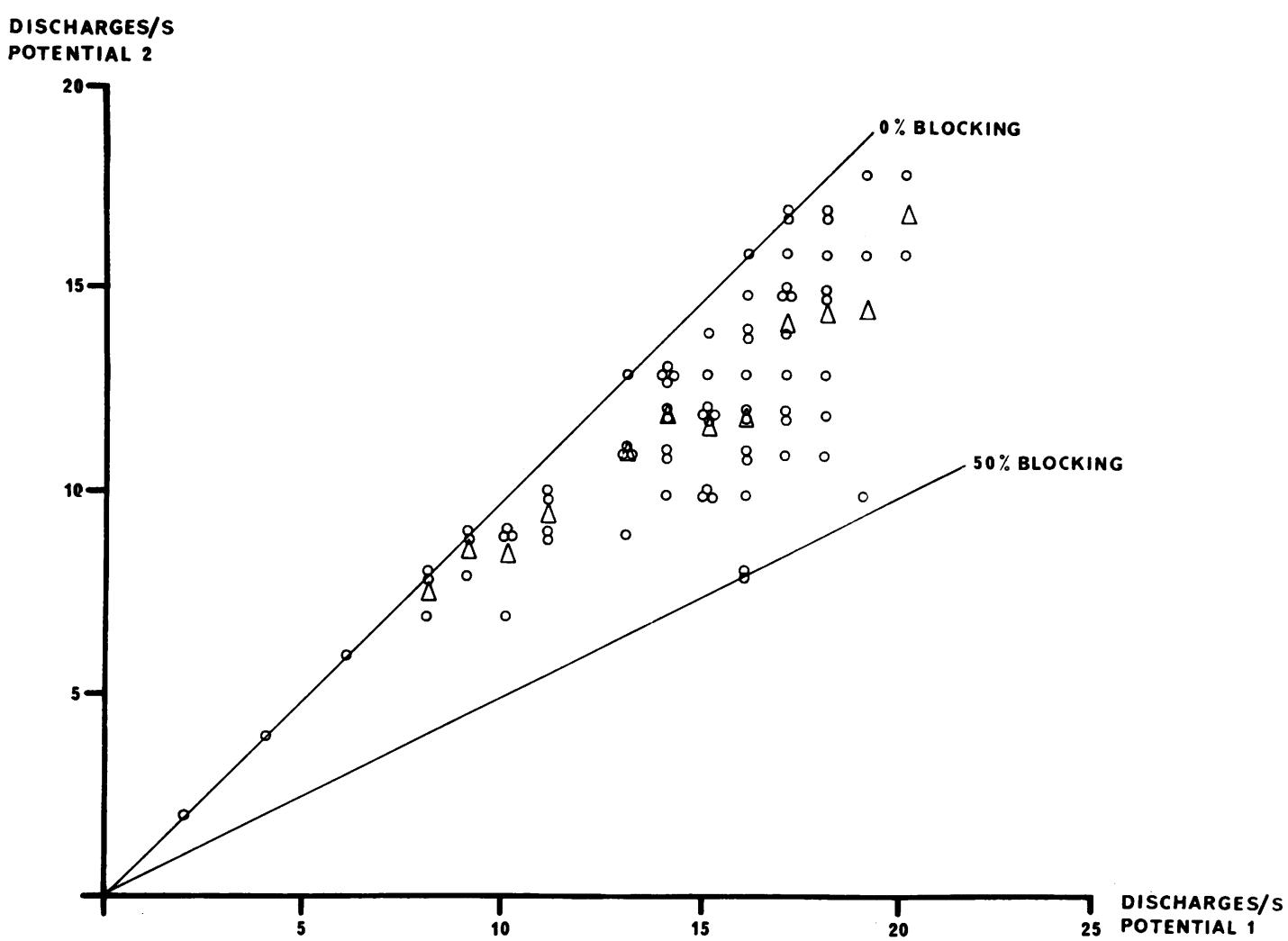

FIG. 5. The influence of increasing innervation rate on the degree of blocking of a potential during maximal effect of edrophonium. The same potential pair as in Fig. 2. The recordings were obtained during $80 \mathrm{~s}$. There is a marked difference in the sensitivity to a high innervation rate in relation to what is seen in Fig. 2.

ments. Some patients felt slight borborygmi and an unspecific dizziness for some minutes. Only one patient had other cholinergic symptoms such as sweating, salivation, and lacrimation, but these were of a moderate degree.

The effect of edrophonium on jitter and blockings could be either improvement (five experi- ments), status quo (four experiments), or deterioration (two experiments). An example of a marked decrease of the jitter and disappearance of blockings is shown in Fig. 4.

In Fig. 2 was shown a potential pair where the influence of an increasing innervation rate was studied. The same type of experiment was
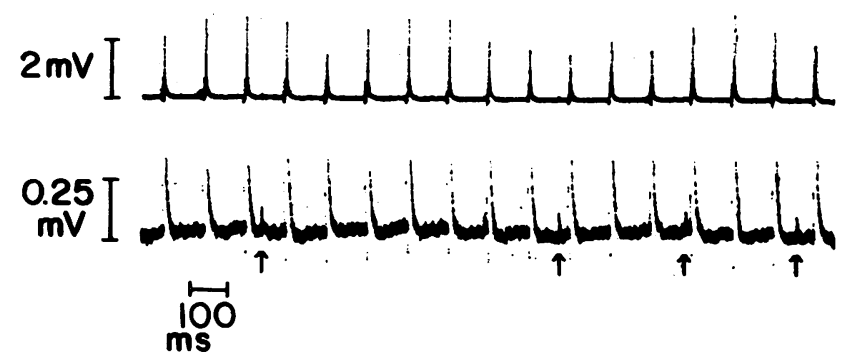

FIG. 6. Recording of the end-plate potentials from a myasthenic inter-costal muscle during repetitive nerve stimulation $(10 \mathrm{~Hz})$. The end-plate potentials were too small to start propagated impulses in the muscle fibre. Note the variability in the amplitude of the end-plate potentials. From Elmqvist et al. (1964) (by permission of The Journal of Physiology (London.)) 
repeated with this potential pair during the maximal effect of edrophonium (Fig. 5). At frequencies below $7 \mathrm{~Hz}$ there were no blockings. The degree of blocking increased with increasing innervation rate but was of a moderate degree even at as high innervation rates as $20 \mathrm{~Hz}$.

One of the patients in the experiments where the jitter and degree of blocking increased after edrophonium was the one who showed the most pronounced cholinergic symptoms. In one patient two edrophonium experiments were performed with an interval of $45 \mathrm{~min}$ and recording was made from two different potential pairs in the same muscle. In the first experiment the jitter and degree of blocking increased. In the second experiment the reaction was the reverse.

\section{DISCUSSION}

An increase of the jitter has been observed in some of the potential pairs in all patients with myasthenia gravis. This phenomenon is a sign of abnormal neuromuscular transmission.

Elmqvist et al. (1964) recorded the end-plate potentials from in vitro preparations of human intercostal muscle. They found a great variability in the amplitude of successive end-plate potentials on electrical stimulation of the nerve (Fig. 6). This was interpreted as an effect of variations in the quantal content of the acetylcholine set free at each nerve impulse. End-plate potentials of sufficient amplitude to initiate action potentials did so with a considerable variability in the latency between the stimulus and the action potential, some end-plate potentials failing to give a muscle response (Fig. 7). There was a more or less random occurrence of different latencies and blockings (Elmqvist, personal communication).

Obviously the recording shown in Fig. 7 demonstrates a jitter of the same type as that reported in this paper. No quantitative comparison can be made between recordings from end-plates in vitro at $21^{\circ} \mathrm{C}$ and in vivo at $37^{\circ} \mathrm{C}$. It is clearly seen in Fig. 7 that the action potentials are triggered at different degrees of depolarization, which may depend on the differences in rate of rise of end-plate potentials of different sizes; a fast rate of rise initiates the action potentials earlier. If, besides, there are spontaneous fluctuations in the trigger level, the effect of these

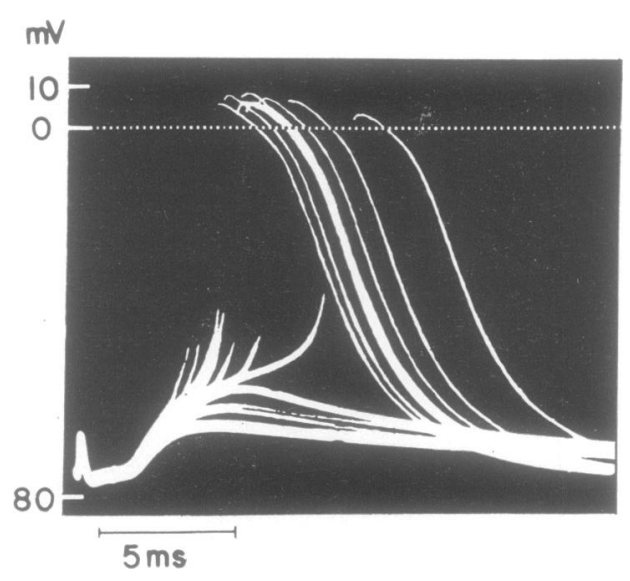

FIG. 7. End-plate potentials and action potentials recorded intracellularly near the end-plate of a myasthenic fibre of an in vitro human inter-costal preparation during indirect stimulation at 5/s. Normal perfusion solution at $21^{\circ} \mathrm{C}$. Superimposed sweeps. About half of the end-plate potentials gave rise to action potentials, while the others failed to do so. Action potentials with different latencies and blockings occurred in approximately random order Elmqvist, personal communication). The latency variation is the same phenomenon as the jitter. From Elmqvist et al. (1964) (by permission of The Journal of Physiology (London)).

fluctuations on the jitter must be increased with decreasing rate of depolarization of the end-plate potential. It is thus probable that the variability in the size of the end-plate potentials must be the main reason for the increase in the jitter in myasthenia gravis.

The increase of the degree of blocking during continuous activity is the myasthenic 'fatigue' in the individual motor end-plates. As shown by Elmqvist et al. (1964), the amplitude of the endplate potential decreases during continuous stimulation and this is the explanation of the increase in blockings as well as of the jitter increase. At a given innervation rate these changes are relatively slow, of course depending on the severity of the affection of the particular end-plates. However, when the innervation rate was abruptly increased, the jitter and degree of blocking increased within seconds and decreased as fast when the innervation rate was lowered. The explanation must be a sudden change in the 
amplitude of the end-plate potential. There must have been a discrepancy between the rate of emptying and filling of the readily releasable fraction of acetylcholine.

Edrophonium inhibits the enzymatic breakdown of acetylcholine and thereby increases the amplitude and duration of the end-plate potential. The experimental results, where the jitter and degree of blocking decreased after injection of edrophonium, must then be explained as an initially insufficient end-plate potential now reaching the trigger level. The increased blocking noted in two patients corresponds to the cholinergic reaction to the edrophonium test. It may be explained as a development of depolarization block, due to remaining effect of acetylcholine from the preceding discharge. These patients were on oral medication with cholinesterase inhibitors and the dose for that specific end-plate might then have been too high.

The jitter recordings in the different patients have shown that the different end-plates in a particular muscle are affected by the disease to a different degree (Table). Some potential pairs may show a very high jitter with frequent blockings, others have jitter within the normal range. However, those potential pairs which have a normal or moderately increased jitter are much easier to record than those with a very high jitter and a high degree of blockings. With frequent blockings it may be difficult to ascertain that the two potentials belong to the same motor unit. In severe cases this will lead to a bias towards lower jitter measurement values. This is the reason why no measurement values have been given, besides the fact that the pathological jitter increases during activity and the fact that the patients were on cholinesterase inhibitor therapy and the investigation was made at a variable time after the last drug dose.

Blom and Ringqvist (1971) made jitter recordings after a drug free interval of 12 hours and found a correlation between the size of the jitter and the severity of the disease.

An increase of the jitter may have other causes than a defective neuromuscular transmission (Stålberg and Ekstedt, 1973) but if the jitter in all end-plates is normal in a weak muscle the diagnosis of myasthenia gravis can be excluded.
The skilful technical assistance of Mr. Gösta Lovén and_Yvonne Markestad is gratefully acknowledged.

\section{REFERENCES}

Blom, S., and Ringqvist, I. (1971). Neurophysiological findings in myasthenia gravis. Single muscle fibre activity in relation to muscular fatiguability and response to anticholinesterase. Electroencephalography and Clinical Neurophysiology, 30, 477-487.

Czekajewski, J., Ekstedt, J., and Stålberg, E. (1969). Oscilloscopic recording of muscle fiber action potentials. The window trigger and the delay unit. Electroencephalography and Clinical Neurophysiology, 27, 536-539.

Ekstedt, J. (1964). Human single muscle fiber action potentials. Acta Physiologica Scandinavica. 61, Suppl. 226.

Ekstedt, J., Häggqvist, P., and Stålberg, E. (1969). The construction of needle multi-electrodes for single fiber electromyography. Electroencephalography and Clinical Neurophysiology, 27, 540-543.

Ekstedt, J., Lindholm, B., Ljunggren, S., and Stålberg, E. (1971). The jittermeter: a variability calculator for use in single fiber electromyography. Electroencephalography and Clinical Neurophysiology, 30, 154-158.

Ekstedt, J., Nilsson, G., and Stålberg, E. (1974). Calculation of the electromyographic jitter. Journal of Neurology, Neurosurgery, and Psychiatry, 37, 526-539.

Ekstedt, J., and Stålberg, E. (1965). The diagnostic use of single muscle fiber recording and the neuromuscular jitter in myasthenia gravis. In 6th International Congress of Electroencephalography and Clinical Neurophysiology, Vienna, 1965. Communications, pp. 669-672. Wiener Medizinische Akademie: Vienna.

Ekstedt, J., and Stålberg, E. (1967). Myasthenia gravis. Diagnostic aspects by a new electrophysiological method. Opuscula Medica, 12, 73-76.

Ekstedt, J., and Stålberg, E. (1969). The effect of nonparalytic doses of D-tubocurarine on individual motor end-plates in man, studied with a new electrophysiological method. Electroencephalography and Clinical Neurophysiology, 27, 557-562.

Ekstedt, J., and Stålberg, E. (1973). Single fibre electromyography for the study of the microphysiology of the human muscle. In New Developments in Electromyography and Clinical Neurophysiology, Vol. 1, pp. 89-112. Edited by J. E. Desmedt. Karger: Basel.

Elmqvist, D., Hofmann, W. W., Kugelberg, J., and Quastel, D. M. J. (1964). An electrophysiological investigation of neuromuscular transmission in myasthenia gravis. Journal of Physiology, 174, 417-434.

Harvey, A. M., and Masland, R. L. (1941). A method for the study of neuromuscular transmission in human subjects. Bulletin of the Johns Hopkins Hospital, 68, 81-93.

Lindsley, D. B. (1935). Myographic and electromyographic studies of myasthenia gravis. Brain, 58, 470-482.

Stålberg, E. (1966). Propagation velocity in human muscle fibres in situ. Acta Physiologica Scandinavica, 70, Suppl. 287.

Stålberg, E., Ekstedt, J., and Broman, A. (1971). The electromyographic jitter in normal human muscles. Electroencephalography and Clinical Neurophysiology, 31, 429-438.

Stålberg, E., and Ekstedt, J. (1973). Single fibre EMG and microphysiology of the motor unit in normal and diseased human muscle. In New Developments in Electromyography and Clinical Neurophysiology, Vol. 1, pp. 113-129. Edited by J. E. Desmedt. Karger: Basel.

Stålberg, E., and Hansson, O. (1973). Single fibre EMG in juvenile myasthenia gravis. Neuropädiatrie, 4, 20-29. 